\title{
Flower Waste Degradation Using Microbial Consortium
}

\author{
Jadhav A. R.*, Chitanand M. P., Shete H. G. \\ *Post Graduate Department of Microbiology, N. S. B. College, Nanded (M.S.), India.
}

\begin{abstract}
Huge amounts of flowers are offered in temples in India creating a large amount of flower waste. The temple wastes are released in the water bodies or dumped at the available places of land which creates severe environmental pollution and health hazards. Hence present study was under taken to develop efficient microbial consortium for degradation of flower waste. In nature, microorganisms do not live isolated, they coexist with many different microorganisms establishing relationships with each other which help them to degrade highly complex organic compound to simple stable end products. Therefore in the present work instead of individual isolates an attempt is made to develop microbial consortium for degradation of flower waste. Soil samples were collected from the area near the temple. Serial dilutions of soil were prepared. Bacteria were isolated by spreading one $\mathrm{ml}$ of each dilution on sterile nutrient agar plates. Soil isolates obtained were tested for its ability to degrade the flower waste. The flower waste was collected from the different temples, it was dried and $1 \%$ sterile, dried powder of this flower waste was added in the minimal medium (without carbon source). The soil isolates were streak inoculated on this flower waste agar medium. Isolates showing prominent growth on this medium were selected for consortium development. Various combinations of soil isolates were used. Five percent inoculum of different consortia was spread on flower waste chambers. It was incubated aerobically. Degradation was checked after specific time interval. Microbial consortium helped in reducing the time required for degrading large amount of flower waste. With this approach we can prepare good quality bio manure without causing any harm to the environment.
\end{abstract}

Key words: Flower wastes, Bacterial consortium, Biofertilizer, Pot experiment.

\section{Introduction}

Floral waste generation occur largely during functions, worships, ceremonies, festivals, etc. This creates heaps of waste which are carelessly thrown on roadsides. Degradation of floral waste is a very slow process as compared to kitchen waste degradation. Also it causes eel and worm development at the site. Therefore there is a need of proper and eco-friendly process for floral waste degradation. Increasing population naturally increase the demand for agro products. Crop production is generally increased by using fertilizers. Use of chemical fertilizers causes its biomagnifications in the food chain. Constant use of chemical fertilizers decreases the soil fertility. They may also result hazards occasionally. Bio/Organic fertilizer is therefore on increasing demand.

The fertilizers are used to improve the fertility of the land using biological wastes, hence the term biofertilizers, and biological wastes do not contain any chemicals which are detrimental to the living soil. Biofertilizers are environmental friendly fertilizers that not only prevent damages to natural sources but help, to some extent, in cleaning the nature from precipitated chemical fertilizers (Food and Agricultural Organization, 2008). The role of plant nutrients in crop production is well-established and 16 essential plant nutrients have to be available to the crops in required quantities to achieve the yield target. Many studies have also emphasized on the importance of $\mathrm{N}, \mathrm{P}$ and $\mathrm{K}$ in enhancing the natural ability of plants to resist stress from drought and cold, pests and diseases ( Debosz et al., 2002; Tsai et al., 2007). Essential plant nutrients such as N, P, K, Ca, Mg and $\mathrm{S}$ are called macronutrients, while $\mathrm{Fe}, \mathrm{Zn}, \mathrm{Cu}, \mathrm{Mo}, \mathrm{Mn}, \mathrm{B}$ and $\mathrm{Cl}$ are called micronutrients. It is necessary to assess the capacity of a soil to supply the lacking amounts of needed plant nutrients. This is also important to produce a good biofertilizer formulation and to supply nutrients that can improve soil health and fertility of plants.

\section{Materials and Methods}

\section{Screening for floral waste degrading microorganisms.}

Soil sample was collected from temple area. Ten grams of sample soil were taken into a $250 \mathrm{ml}$ of conical flask, and $90 \mathrm{ml}$ of sterile distilled water was added into it. The flask was shaken for $10 \mathrm{~min}$ on a rotary shaker. One milliliter suspension was added to $\mathrm{ml}$ of via and shaken for $2 \mathrm{~min}$. serial dilution technique was performed up to 10-7 an aliquot $(0.1 \mathrm{ml})$ if this suspension was spread on flower waste agar plates. Plates were incubated for $24 \mathrm{hrs}$ at $37^{\circ} \mathrm{c}$. After incubation the colonies developed on the flower waste agar plate were observed for different characteristics of colonies such as shape, size, elevation, surface, margin, color, odor, pigmentation, etc and gram's staining. Total eight bacterial isolates out of all developed colonies on the flower 
waste agar plate were selected as flower waste degrading microorganisms. ( Navarrete-Bolaños, J.L., et., al., 2007 and Jelin J., et., al., 2013 )

\section{Development of Consortium}

Different combinations of eight bacterial isolates were prepared and used for biofertilizer preparation. Out of which, the combination giving rapid degradation of flower wastes was selected for the consortium preparation. A loopful growth from $24 \mathrm{hrs}$ old bacterial culture of different organisms in selected combination was inoculated in minimal broth containing flower waste. Broth was incubated at $37{ }^{0} \mathrm{c}$ for 48 hrs. After incubation, this broth was used as consortium and then $20 \%(\mathrm{v} / \mathrm{w})$ of this consortium as inoculum was added to the flower waste. ( Navarrete-Bolaños, J.L., et., al., 2007 and Pavan k. P., et., al., 2012 ).

\section{Designing of degradation chamber}

All organic material wastes available in form flowers were collected. These flower wastes were first crushed with the help of crusher machine before being piled. Material composts best when it is very small in size. Soft, succulent tissues did not need chopping into very small pieces because they decompose rapidly. All the ingredients are mixed together, except. These grind particle mix with a small amount of soil ( soil used because soil has ability to absorb moisture and provided suitable condition for growth of microorganism ) mix the mixture uniformly. Two glass chambers of dimension $10.5 \times 10 \times 5.5 \mathrm{~cm}$ were selected. Then the first layer of coconut coir of height $2 \mathrm{~cm}$ was prepared at the bottom of the chambers for maintaining aerobic conditions. Coconut coir layer was covered by garden soil $(2 \mathrm{~cm})$. Third layer was made by using flower waste inoculated with $20 \%$ consortium. Alternative layers of soil and flower wastes inoculated with consortium were given as above. Second chamber was prepared as control chamber by following same procedure using flower waste without consortium. ( Boraste A., et., al., 2009 and Gurav M. V., et., al., 2011 ). After complete degradation of flower wastes the degraded material is used as a biofertilizer.

\section{Chemical analysis}

Samples from the chambers after degradation were tested for $\mathrm{pH}$, total minerals and $\mathrm{N}, \mathrm{P}, \mathrm{K}$ content. The total nitrogen, phosphorus and potassium (NPK) content of samples were analyzed according to the following methods. Nitrogen was determined by the acid combustion elemental analysis method using the macro kjeldahl system ( Tandon, H. L. S. et., al., 1993 ). The phosphorus, potassium and other micronutrients were digested using the acid digestion method and analyzed spectrophotometrically using EPA method ( Tandon, H. L. S. et., al., 1993 ). The $\mathrm{pH}$ value was measured in a 5-fold dilution of distilled water equilibrated with the sample for an hour with a $\mathrm{pH}$ meter. $\mathrm{C} \%$ and $\mathrm{N} \%$ was determined by APHA method ( APHA, 2005).

\section{Efficacy of biofertilizers}

Efficacies for the biofertilizers were carried out for several days. Soil for this experiment was garden soil having neutral $\mathrm{pH}$ and sufficient moisture content. A local variety of wheat, green gram and Jowar were used as test plants. The experimental design was the completely randomized design with two replicates. Two sets of pots were prepared for each test plants 1 by using prepared biofertilizer and another by without using biofertilizer as control. Then fix measured amount of good qualities seeds of all test plants were planted in respective pots. The pots were then watered regularly for 7 days. During harvesting, the plants were carefully uprooted from each pot and the plant height was recorded. ( Siti Zulaiha H., et., al., 2013 )

\section{Results and Discussion}

Eight different colonies developed on minimal medium were selected for combinations of consortium. Combination of four isolates giving rapid growth on minimal medium was selected for consortium preparation. Selected microorganisms are very efficient to cause floral waste degradation and to convert it into nitrogen potash fertilizer. The fertilizer thus prepared is Eco-friendly, which is free from pollutants, toxic products, harmful gases and disease causing agent. It is easy to handling and it does not cause any harm to humans as well as animals. It is cost effective and easy to prepare.

It has raised NPK values of the soil, which is a main requirement of biofertilizers. Biofertilizers enhance the nutrient availability to crop plants (by processes like fixing atmosphere $\mathrm{N}$ or dissolving $\mathrm{P}$ present in the soil); and impart better health to plants and soil thereby enhancing crop yields in a moderate way. It is a natural method without any problems like salinity and alkalinity, soil erosion etc. Prepared microbial consortium can be used to degrade flower rapidly, thus to avoid generation of heaps of flowers and other temple waste. The degraded material has the high values of N, P, and K content so it can be used as a nitrogen potash biofertilizer. Prepared microbial consortium can be used to degrade flower rapidly, thus to avoid generation of heaps of flowers and other temple waste. The degraded material has the high values of $\mathrm{N}, \mathrm{P}, \mathrm{K}$ content so it can be used as a nitrogen potash biofertilizer. 


\section{Observation Tables}

1. Cultural and Morphological characteristics:

\begin{tabular}{|l|l|l|l|l|}
\hline Sr. No. & Isolates & Morphology & Gram's Nature & Motility \\
\hline 01 & Isolates I & Rods & Gram negative & Motile \\
\hline 02 & Isolates II & Rods & Gram negative & Motile \\
\hline 03 & Isolates III & Rods & Gram positive & Non-Motile \\
\hline 04 & Isolates IV & Rods ( in chains ) & Gram positive & Non-Motile \\
\hline
\end{tabular}

\section{Effect of microbial consortium on flower waste degradation}

\begin{tabular}{|l|l|l|l|}
\hline Sr. No. & Days & Height of content in chamber in $\mathrm{cm}$ \\
\hline & & F. W. + Soil + Consortium & F. W. + Soil \\
\hline 01 & 1 & 30 & 30 \\
\hline 02 & 3 & 26 & 30 \\
\hline 03 & 5 & 23 & 29 \\
\hline 04 & 7 & 21 & 28 \\
\hline 05 & 9 & 17 & 27 \\
\hline
\end{tabular}

\section{Chemical Analysis}

\begin{tabular}{|l|l|l|l|l|l|l|}
\hline $\begin{array}{l}\text { Sr. } \\
\text { No. }\end{array}$ & \multicolumn{1}{|c|}{ Sample } & pH & $\begin{array}{l}\text { Mineral salts } \\
\text { m-mhos/cm }\end{array}$ & $\begin{array}{l}\text { Nitrogen } \\
\text { content } \%\end{array}$ & $\begin{array}{l}\text { Phosphorous } \\
\text { Kg/Hector }\end{array}$ & $\begin{array}{l}\text { Potassium } \\
\text { Kg/Hector }\end{array}$ \\
\hline 01 & Soil with Microbial Consortium & 7.4 & 0.53 & 0.139 & 0.83 & 7848 \\
\hline 02 & Soil with Flower waste & 7.3 & 0.29 & 0.112 & 6.66 & 1236 \\
\hline 03 & Soil & 8.3 & 0.11 & 0.078 & 0.80 & 2069 \\
\hline
\end{tabular}

\section{Effect of Biofertilizer on Plant Growth}

\begin{tabular}{|c|c|c|c|c|c|c|c|c|c|}
\hline $\begin{array}{l}\text { Sr. } \\
\text { No. }\end{array}$ & Plants & Samples & \multicolumn{7}{|c|}{ Height of Shoot length in $\mathrm{cm}$} \\
\hline & & & \multicolumn{7}{|c|}{ Days of Incubation } \\
\hline & & & 1 & 2 & 3 & 4 & 5 & 6 & 7 \\
\hline \multirow[t]{2}{*}{01} & \multirow{2}{*}{ Wheat } & Soil & -- & -- & 0.50 & 1.50 & 3.30 & 5.00 & 12.50 \\
\hline & & Soil + Biofertilizer & -- & -- & 0.75 & 2.50 & 4.00 & 7.00 & 14.50 \\
\hline \multirow[t]{2}{*}{02} & \multirow{2}{*}{ Jowar } & Soil & -- & -- & -- & 0.50 & 2.00 & 4.00 & 6.00 \\
\hline & & Soil + Biofertilizer & -- & -- & -- & 0.75 & 2.50 & 5.00 & 7.40 \\
\hline \multirow[t]{2}{*}{03} & \multirow{2}{*}{$\begin{array}{l}\text { Green } \\
\text { gram }\end{array}$} & Soil & -- & -- & -- & 0.50 & 2.00 & 7.00 & 7.65 \\
\hline & & Soil + Biofertilizer & -- & -- & -- & 0.65 & 3.00 & 9.00 & 10.30 \\
\hline
\end{tabular}

Figure 1 :Design of degradation chamber.

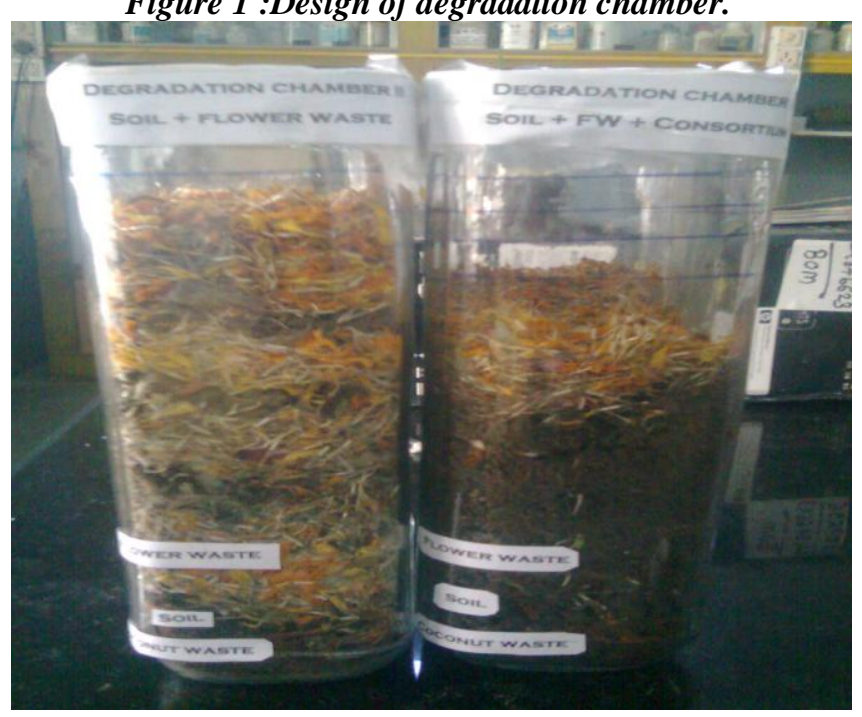




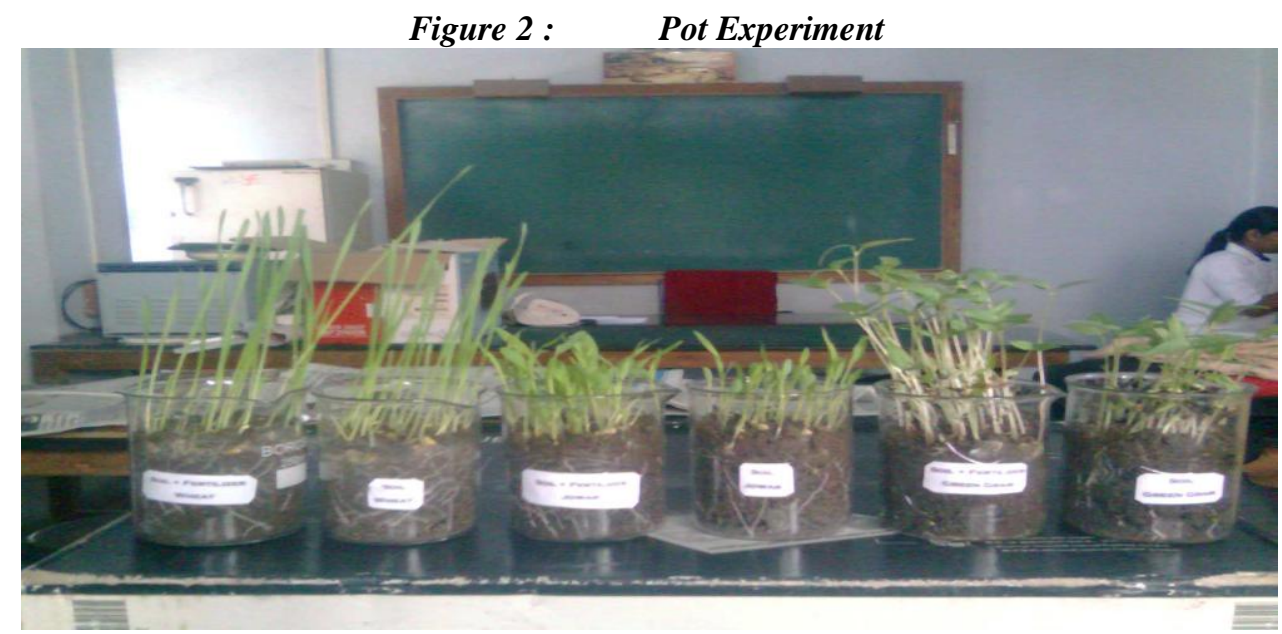

Acknowledgements

the work.

We are thankful to the Principal, Netaji Subhashchandra Bose College, Nanded for the support during

\section{References}

[1]. Boraste A., Vamsi K.K., Jhadav A., Khairnar Y., Gupta N., Trivedi S., Patil P., Gupta G., Gupta M., Mujapara A.K., Joshi B. ( 2009 ).Biofertilizers: A novel tool for agriculture. International Journal of Microbiology Research, ISSN: 0975-5276, Volume 1, Issue 2, 2009, pp-23-31.

[2]. Crueger, W., Crueger, A. (1990). Biotechnology: A Textbook of Industrial Microbiology, 2nd Ed. Science Tech Publishers (Madison).

[3]. Debosz, K., Petersen, S. O., Kure, L. K. and Ambus, P. (2002). Evaluating effects of sewage sludge and household compost on soil physical, chemical and microbiological properties. Application of Soil Ecology, 19 (3), 237-248.

[4]. Gurav M. V., Pathade G. R., Production of Vermicompost from Temple Waste (Nirmalya): A Case Study. ( 2011 ). Universal Journal of Environmental Research and Technology, Volume 1, Issue 2: 182-192.

[5]. Jelin J., Selvakumar T. A., Dhanarajan M. S., ( 2013 ). Phytological Analysis For Designinig A Microbial Consortium To Enhance Plant Growth. International Journal of Chem Tech Research. Vol.5, No.3, pp 1370-1375, April-June 2013.

[6]. Navarrete-Bolaños, J.L., Serrato-Joya, O., Botello-Alvarez, E. Jimenez-Islas, H., Cardenas-Manriquez, M., Conde-Barajas, E., RicoMartínez, R., Analyzing microbial consortia for biotechnological processes design. Communicating Current Research and Educational Topics and Trends in Applied Microbiology. A. Méndez-Vilas (Ed.) 2007, pp: 437 - 449.

[7]. Pavan kumar Pindi, SDV Satyanarayana ( 2012 ). Liquid Microbial Consortium- A Potential Tool for Sustainable Soil Health. J Biofertilizers and Biopesticides. Vol. 3, Issue 4.

[8]. Siti Zulaiha H., Hassan M. A., Sheikh I. S. A., Siti Hajar M. S., Mohamad Roji S., Ramlan A., ( 2013 ). Agriculture wastes conversion for biofertilizer production using beneficial microorganisms for sustainable agriculture applications. Malaysian Journal of Microbiology, Vol. 9(1) 2013, pp. 60-67.

[9]. Tandon, H. L. S. (1993). In: Tandon, H.L.S. (Eds.), Methods of analysis of soils, plants, waters and fertilizers. Fertilizer Development and Consultation Organization, New delhi, India, pp. 36-48.

[10]. Tsai, S.-H., Liu, C.-P. and Yang, S.-S. (2007). Microbial conversion of food wastes for biofertilizer production with thermophilic lipolytic microbes. Renewable Energy, 32, (6), 904-915. 